\title{
CRESCIMENTO E PRODUTIVIDADE DE ALGODOEIRO SUBMETIDO A CLORETO DE MEPIQUAT E DOSES DE NITROGÊNIO $\left({ }^{1}\right)$
}

\author{
ITAMAR ROSA TEIXEIRA $\left({ }^{2}\right)$; HAMILTON KIKUTI $\left({ }^{3}\right)$; ALUÍZIO BORÉM $\left({ }^{4}\right)$
}

\begin{abstract}
RESUMO
Em regiões com condições climáticas favoráveis como de cerrado, tem-se verificado excessivo crescimento vegetativo do algodoeiro, principalmente quando associado à utilização de elevadas doses de $\mathrm{N}$, justificando a utilização de substâncias reguladoras de crescimento para obtenção de plantas mais produtivas e com porte adequado à colheita mecanizada. Neste trabalho, objetivou-se avaliar o crescimento e a produtividade do algodoeiro cv. FMX 986, submetido às doses de $\mathrm{N}$ e cloreto de mepiquat, nas condições edafoclimáticas do cerrado goiano. Para tanto, o delineamento experimental utilizado foi de blocos casualizados, em esquema fatorial $4 \times 2$, envolvendo a combinação de quatro doses de $\mathrm{N}(0,60,120$ e 180 $\left.\mathrm{kg} \mathrm{ha}^{-1}\right)$ na presença e ausência de cloreto de mepiquat $\left(50 \mathrm{~g} \mathrm{ha}^{-1}\right)$, com quatro repetições. O cloreto de mepiquat foi aplicado em três vezes, aos 40,60 e 80 dias após a emergência das plantas, utilizando 12,5 $\mathrm{g} \mathrm{ha}^{-1}, 17,5 \mathrm{~g} \mathrm{ha}^{-1}$ e $20 \mathrm{~g} \mathrm{ha}^{-1}$ respectivamente. Conclui-se que com as doses de $\mathrm{N}$ aumentaram-se a massa média de capulhos, a massa média de cem sementes e a produtividade do algodoeiro. Com a aplicação do regulador de crescimento é diminuído o tamanho da planta e promovidos acréscimos de rendimento da ordem de $12 \%$. Na dose de $131 \mathrm{~kg} \mathrm{ha}^{-1}$ de $\mathrm{N}$ foi obtido maior rendimento de algodão $\left(3.633 \mathrm{~kg} \mathrm{ha}^{-1}\right)$. Não houve influência do regulador de crescimento e da adubação nitrogenada no índice de produtividade e precocidade.
\end{abstract}

Palavras-chave: Gossipium hirsutum, regulador de crescimento, altura de plantas, produtividade.

\section{ABSTRACT \\ PRODUCTIVITY AND COTTON GROWTH SUBMITTED TO MEPIQUAT CHLORIDE AND N DOSES}

\begin{abstract}
Excessive vegetative growth has been verified in cotton when associated with high $\mathrm{N}$ doses in favorable climatic regions, justifying the utilization of growth regulators that promote higher productivity and adequate canopy to mechanization. The objective of this study was to evaluate the productivity and cotton growth submitted to mepiquat chloride and $\mathrm{N}$ doses. For that, the experimental design was a complete block in a factorial of $4 \times 2$, with four nitrogen doses $\left(0,60,120\right.$ e $\left.180 \mathrm{~kg} \mathrm{ha}^{-1}\right)$ with and without mepiquat chloride $\left(50 \mathrm{~g} \mathrm{ha}^{-1}\right)$. The growth regulator mepiquat chloride was utilized at 40,60 ad 80 days after plant emergence with $12,5 \mathrm{~g} \mathrm{ha}^{-1}, 17,5 \mathrm{~g} \mathrm{ha}^{-1}$ e $20 \mathrm{~g} \mathrm{ha}^{-1}$, respectively. It was verified that $\mathrm{N}$ doses increased cotton boll mass, 100 -seeds mass and yield. The application of the growth regulator reduces plant size and it promotes increments of yield by $12 \%$. The dose of $131 \mathrm{~kg} \mathrm{ha}^{-1} \mathrm{~N}$ allowed obtaining the largest productivity $\left(3.633 \mathrm{~kg} \mathrm{ha}^{-1}\right)$. There was no influence of the growth regulator and of the $\mathrm{N}$ fertilizer on productivity index and precocity.
\end{abstract}

Key words: Gossipium hirsutum, grown regulator, plant height, productivity.

(1) Recebido para publicação em 8 de abril de 2006 e aceito em 23 de junho de 2008.

$\left(^{2}\right)$ Universidade Estadual de Goiás - UEG, Unidade Universitária de Ipameri. Rodovia GO 330, Km 241, Anel Viário, 75780-000 Ipameri (GO). E-mail: itamar.texeira@ueg.br $\left(^{*}\right)$ Autor correspondente.

$\left({ }^{3}\right)$ Universidade Estadual de Mato Grosso do Sul, Unidade Universitária de Cassilândia. Rodovia MS 306, Km 06, 79540-000, Cassilândia (MS). E-mail: hkikuti@uems.br

$\left({ }^{4}\right)$ Universidade Federal de Viçosa, Departamento de Fitotecnia, 36571-000 Viçosa (MG). 


\section{INTRODUÇÃO}

A cotonicultura brasileira vem se destacando atualmente como uma atividade em vigoroso processo de expansão e com excepcionais resultados técnicos e econômicos. Na última safra, 2006/2007, foram produzidos 1,5 milhões de toneladas de algodão em pluma (CONAB, 2008), sendo a região do cerrado, atualmente, a principal região produtora no país.

Dentre os fatores responsáveis pela produtividade do algodoeiro, destaca-se o emprego de nutrientes, estando o $\mathrm{N}$ entre os requeridos em mais quantidade, sendo por isso considerado importante fator decisivo na obtenção de elevados patamares de produtividades.

Respostas à adubação nitrogenada em algodão são variáveis, pois há casos de incrementos de produtividade com doses superiores a $150 \mathrm{~kg} \mathrm{ha}^{-1}$ de N (Silva et al., 2001a,b; Lamas e Staut, 2005), e por outro lado, de não influência no rendimento de seus componentes.

A utilização de cultivares de algodão de grande produtividade tem levado à utilização de cada vez mais nutrientes, dentre os quais o N. Porém, devido ao excesso de $\mathrm{N}$ associado às condições climáticas favoráveis, pode resultar crescimento vegetativo excessivo do algodoeiro (BEltrão, 1998), com interferência negativa na produtividade. Neste caso, o uso de substâncias reguladoras como o cloreto de mepiquat torna-se indispensável na redução do porte das plantas e por propiciar maior distribuição de assimilados para os diferentes drenos produtivos, com reflexos positivos na produção.

Os reguladores de crescimento vegetais são substâncias químicas sintéticas que alteram o balanço hormonal das plantas, reduzindo-se o crescimento longitudinal indesejável da parte área das plantas, sem diminuir a produtividade (REDDY et al., 1995). Em geral, provocam atividade antigiberelina, como é o caso do cloreto de mepiquat (1.1 - dimetil-piperidinium chloride), inibidor de uma das enzimas envolvidas na síntese do ácido giberélico, fitormônio promotor e estimulante do crescimento da planta (LAMAS, 2001).

Com o cloreto de mepiquat pode ser favorecido o equilíbrio entre as partes vegetativas e reprodutivas da planta, com mais aproveitamento dos assimilados pelos frutos (Beltrão, 1998). Com a partição de fotoassimilados entre os diferentes drenos da planta, capulhos, hastes, ramos, etc., pode ser incrementado a produção econômica das plantas, mas, por outro lado, as investigações sobre seus possíveis efeitos na produção ainda são inconsistentes, pois há na literatura relatos de acréscimos de produtividade
(Lamas e Staut, 2005), e em outros, diminuição (Nóbrega et al., 1999). Este fato tem se tornado uma preocupação em regiões algodoeiras no cerrado goiano, onde se utilizam comumente genótipos de grande capacidade produtiva, associados às doses elevadas de $\mathrm{N}$, e não se tem limitação hídrica às plantas. Dessa forma, acredita-se na hipótese que, com a aplicação de $\mathrm{N}$ associado à adequada disponibilidade hídrica, há interferência negativa na produtividade e na qualidade final do produto colhido, bem como na dificuldade na colheita mecanizada. Com o emprego de regulador de crescimento pode-se obter plantas com porte adequado e responsivas à adubação nitrogenada, com garantia de produtividade e produto final de mais qualidade.

Objetivou-se, com este trabalho, avaliar os efeitos de doses de $\mathrm{N}$ e do regulador de crescimento cloreto de mepiquat no crescimento e em algumas características agronômicas do algodão cv. FMX 986 nas condições edafoclimáticas do cerrado goiano.

\section{MATERIAL E MÉTODOS}

O experimento foi realizado na safra 2005/ 2006, em propriedade particular localizada em Ipameri (GO), a $17^{\circ} 43^{\prime \prime} \mathrm{S}$ e $48^{\circ} 09^{\prime \prime} \mathrm{W}$, em altitude de 820 metros, com clima classificado como mesotérmico úmido. Os dados climatológicos estão relacionados na figura 1.

Amostras de um Latossolo Vermelho-Amarelo distroférrico foram coletadas na camada de $0-20 \mathrm{~cm}$ e analisadas quimicamente, cujos resultados são apresentados a seguir: $\mathrm{pH}\left(\mathrm{H}_{2} \mathrm{O}\right): 6,0 ; \mathrm{P}\left(\mathrm{mg} \mathrm{dm}^{-3}\right)$ : 2,0; $\mathrm{K}\left(\mathrm{mg} \mathrm{dm}^{-3}\right): 58 ; \mathrm{Ca}\left(\mathrm{cmol} \mathrm{dm}^{-3}\right): 4,0 ; \mathrm{Mg}\left(\mathrm{cmol} \mathrm{dm}^{-3}\right)$ : 1,2; $\mathrm{Al}\left(\mathrm{cmol} \mathrm{dm}^{-3}\right): 0,0 ; \mathrm{H}+\mathrm{Al}\left(\mathrm{cmol} \mathrm{dm}^{-3}\right): 2,0 ; \mathrm{m}(\%)$ : 0,0; $\mathrm{V}(\%): 65 ; \mathrm{B}\left(\mathrm{mg} \mathrm{dm}^{-3}\right): 0,7 ; \mathrm{Cu}\left(\mathrm{mg} \mathrm{dm}^{-3}\right): 1,5 ; \mathrm{Fe}(\mathrm{mg}$ $\left.\mathrm{dm}^{-3}\right): 32,0 ; \mathrm{Mn}\left(\mathrm{mg} \mathrm{dm}^{-3}\right): 10,2$ e Zn $\left(\mathrm{mg} \mathrm{dm}^{-3}\right): 2,1$.

O delineamento experimental utilizado foi em blocos casualizados em esquema fatorial $4 \times 2$, com quatro repetições. Os tratamentos foram constituídos pela combinação de quatro doses de $\mathrm{N}(0,60,120$ e $\left.180 \mathrm{~kg} \mathrm{ha}^{-1}\right)$ e ausência e presença de cloreto de mepiquat $\left(50 \mathrm{~g} \mathrm{ha}^{-1}\right)$. $\mathrm{O} \mathrm{N}$ foi parcelado em três porções iguais (na semeadura, fonte sulfato de amônio; no desbaste e na floração, fonte uréia).

O regulador de crescimento ( $50 \mathrm{~g}$ de cloreto de mepiquat ha ${ }^{-1}$ ) foi parcelado e aplicado no período da manhã, antes das $9 \mathrm{~h}$, utilizando pulverizador costal, com vazão de $200 \mathrm{~L} \mathrm{ha}^{-1}$. Nas aplicações de cloreto de mepiquat, realizadas aos 40,60 e 80 dias após a emergência das plantas - DAE, foram utilizadas 12,5 $\mathrm{g} \mathrm{ha}^{-1}, 17,5 \mathrm{~g} \mathrm{ha}^{-1}$ e $20 \mathrm{~g} \mathrm{ha}^{-1}$ respectivamente. 

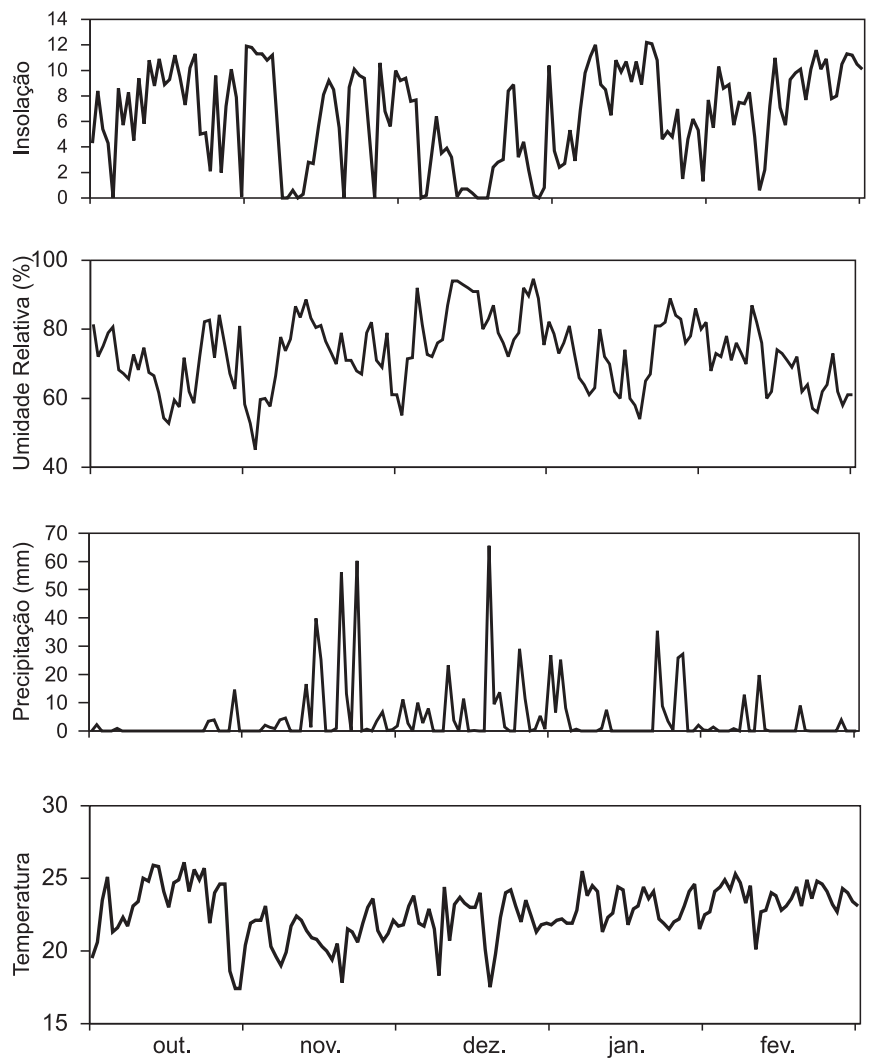

Figura 1. Variação diária da insolação, umidade relativa, precipitação pluvial e temperatura média no período de outubro de 2005 a fevereiro de 2006. (Dados fornecidos pela Estação Climatológica principal de Ipameri (GO), em convênio com o Instituto Nacional de Meteorologia - INMET). Ipameri (GO), 2005/2006.

O preparo do solo foi efetuado com arado escarificador seguido de grade leve. A semeadura foi realizada com distribuição manual das sementes, em sulcos abertos na área de campo por um sulcador acoplado ao trator, realizada em 8 de outubro de 2005, utilizando-se sete sementes por metro, com posterior desbaste aos dez dias após a emergência - DAE, mantendo-se sete plantas por metro.

Cada parcela foi constituída por quatro fileiras de plantas com 5,0 m de comprimento, espaçadas 0,90 $\mathrm{m}$. Como área útil foram consideradas as duas fileiras centrais $(5,0 \times 1,8 \mathrm{~m})$.

A cultivar utilizada foi a FMX-986, de ciclo tardio e crescimento indeterminado (EMBRAPA, 2004). A adubação básica de semeadura, com exceção do N, foi aplicada com base nos resultados da análise de solo, seguindo as recomendações de Pedroso Neto et al. (1999), com o uso de superfosfato simples, cloreto de potássio, sulfato de zinco e boráx. Na adubação de base, a distribuição foi manual, seguida de incorporação. As capinas foram realizadas manualmente, com enxada, e as pragas combatidas conforme manejo integrado, principalmente o bicudo (Anthononus grandis).

Para avaliação do crescimento em altura das plantas, ao longo do ciclo da cultura, foram tomadas dez plantas ao acaso na área útil de cada parcela, aos dois dias antes das aplicações com cloreto de mepiquat e aos dez dias após a sua realização. As medidas foram realizadas com régua graduada, desde o colo da planta até o ápice, considerando-se o meristema apical do eixo principal da planta, com precisão de centímetros.

A colheita foi realizada manualmente, em etapas, sendo quantificado o estande final por ocasião da primeira colheita, contando-se as plantas da área útil em cada parcela. Ao término das etapas de colheita, foi determinada a produtividade do algodão com caroço, pela soma das colheitas realizadas, e seus componentes. Na avaliação dos componentes da produtividade foi coletado aleatoriamente, um capulho por planta em 20 plantas por parcela, no terço médio das plantas, para a obtenção da massa média em capulhos e da massa média de cem sementes.

Determinou-se a precocidade, empregando-se o índice proposto por Fuzatto (1986), citado por PíPOLO et al. (1993), denominado "Índice de Produtividade e Precocidade" (IPP), sendo IPP $=P+p / P M$, em que P é a produção final do tratamento, $\mathrm{p}$ é a produção média do tratamento na primeira colheita, e PM é a produção média final do experimento.

Os dados obtidos foram submetidos à análise de variância e os tratamentos comparados pelo teste de $\mathrm{F}$ a $5 \%$ de probabilidade (regulador de crescimento) e análise de regressão (doses de $\mathrm{N}$ ).

\section{RESULTADOS E DISCUSSÃO}

Para alturas de plantas foram detectadas diferenças significativas com a utilização do cloreto de mepiquat nas diferentes épocas avaliadas, quando, com o emprego do cloreto de mepiquat, promoveu-se menos crescimento das plantas, comparativamente à sua ausência (Tabela 1), o que pode ser atribuído ao fator antigiberilina do produto (LAMAS 2001).

Nas avaliações aos 70 e 78 dias após emergência (DAE), a lavoura estava com um vigoroso crescimento vegetativo, com significância da interação cloreto de mepiquat $\mathrm{x}$ doses de $\mathrm{N}$ para a altura de plantas (Figura 2). Na ausência do cloreto de mepiquat, observou-se aumento das alturas de plantas em resposta ao aumento das doses de $\mathrm{N}$ (Figuras $2 \mathrm{e}$ 3), com valores máximos superiores a 120 e $140 \mathrm{~cm}$, respectivamente. 
Tabela 1. Médias das alturas de plantas de algodão cv. FMX - 986 em função de doses de N, sob condição de ausência e presença de cloreto de mepiquat. Ipameri (GO), 2005/2006

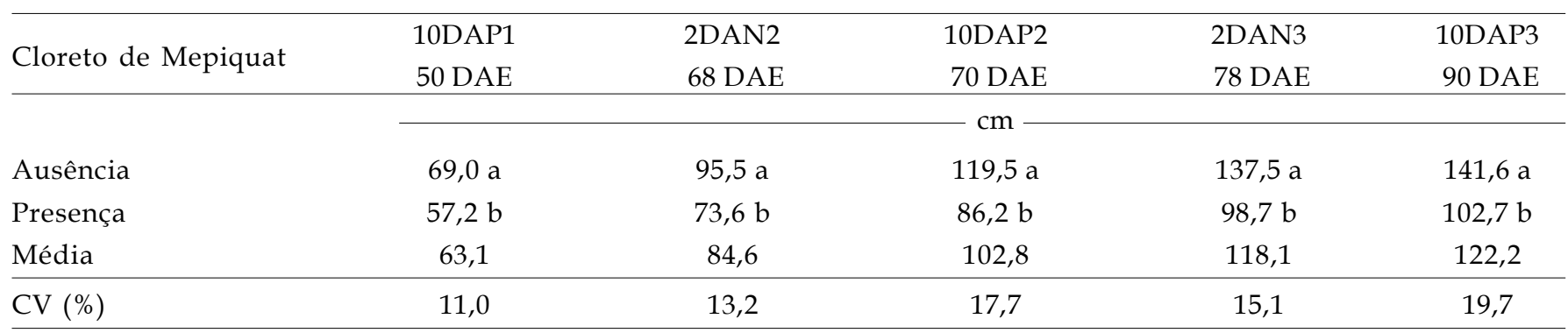

Médias seguidas por letras diferentes, na coluna, diferem entre si pelo teste $\mathrm{F}$ a $5 \%$ de probabilidade.

10DAP1 - dez dias após aplicação 1; 2DAN2 - dois dias antes da aplicação 2;

10DAP2 - dez dias após aplicação 2; 2DAN3 - dois dias antes da aplicação 3;

10DAP3 - dez dias após aplicação 3; DAE - dias após emergência.

Por outro lado, com a utilização do cloreto de mepiquat, os maiores valores de altura de plantas não foram superiores a 90 e $100 \mathrm{~cm}$, nas doses de 99 e 88 $\mathrm{kg}$ de $\mathrm{N} \mathrm{ha}^{-1}$ (Figuras 2 e 3), respectivamente, nas referidas datas de avaliações.

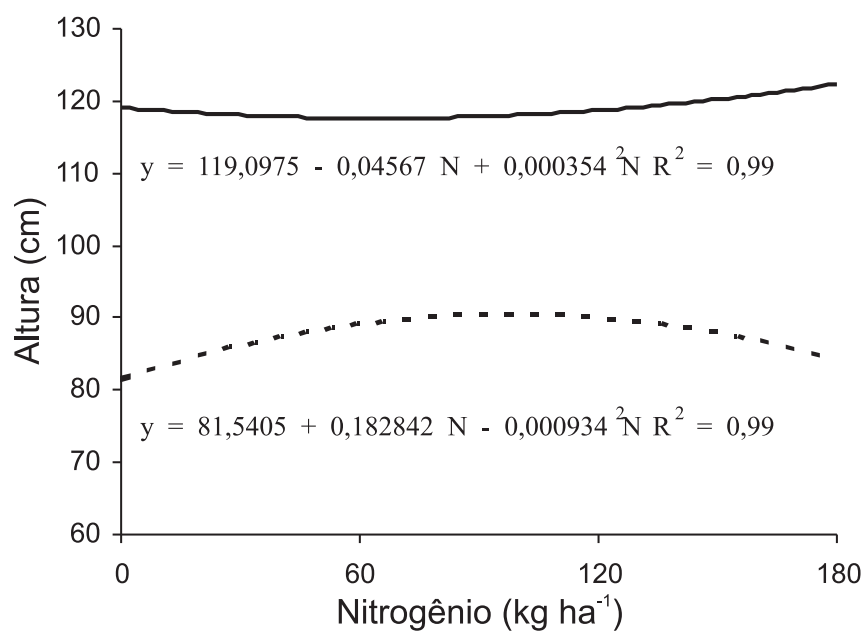

Figura 2. Altura de plantas de algodão cv. FMX-986, em função de doses de N, na ausência (__ ) e presença (_-.-_) de cloreto de mepiquat, na avaliação aos 70 dias após a emergência da cultura. Ipameri (GO), 2005/2006.

O uso do cloreto de mepiquat foi limitante à altura de planta em torno de $65 \%$ e $63 \%$, para as avaliações aos 70 e 78 DAE das plantas, respectivamente, em comparação à sua ausência. Observou-se, ainda, que as doses de N (98 e $\left.88 \mathrm{~kg} \mathrm{ha}^{-1}\right)$, com as quais se propiciou a máxima altura de plantas, estão acima de 30 a $60 \mathrm{~kg} \mathrm{ha}^{-1}$, recomendadas oficialmente para o algodoeiro (EMBRAPA, 1998). Porém, como ressaltam LAMAS e STAUT (2005), genótipos muito produtivos podem ser responsivos às doses superiores a $150 \mathrm{~kg}$ de $\mathrm{N} \mathrm{ha}^{-1} \mathrm{e}$, neste aspecto, a cultivar utilizada se enquadra, por apresentar produtividade superior a $3.200 \mathrm{~kg} \mathrm{ha}^{-1}$ de algodão em caroço, de acordo com EMBRAPA (2004).

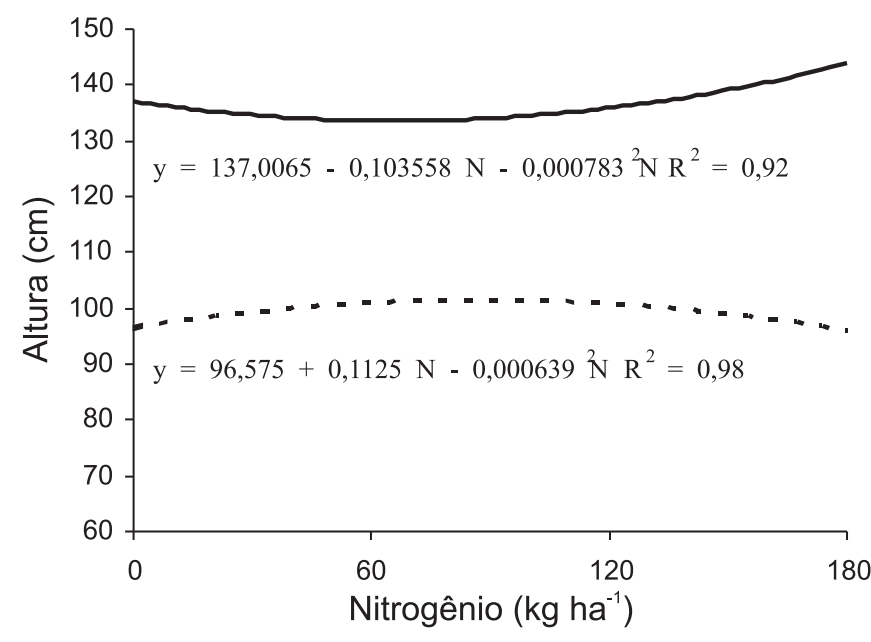

Figura 3. Altura de plantas de algodão cv. FMX - 986, em função de doses de N, na ausência (_ $)$ e presença (_-_- ) de mepiquat, na avaliação aos 90 dias após a emergência da cultura. Ipameri (GO), 2005/2006.

Considerando que o máximo crescimento em altura do algodoeiro ocorreu em torno de 60 e 70 dias da emergência e, sendo esta a fase de mais demanda de $\mathrm{N}$ pelas plantas, pode-se dizer que a dose de $\mathrm{N}$ adequada para este crescimento situou-se em torno de $90 \mathrm{~kg} \mathrm{ha}^{-1}$, sendo também necessária a aplicação do cloreto de mepiquat, visando ao aumento dos números de ramos reprodutivos, em detrimento dos vegetativos.

$\mathrm{Na}$ avaliação realizada aos $90 \mathrm{DAE}$, a altura média das plantas que receberam o regulador foi de $100 \mathrm{~cm}$, enquanto no tratamento sem o produto este valor foi de $140 \mathrm{~cm}$ (Tabela 1). Dessa forma, verificouse redução no crescimento em altura de aproximadamente $38 \%$ com a utilização de cloreto de mepiquat, valor este superior ao de FURLANI JúNIOR et al. (2003), que obtiveram redução de $11,4 \%$ no crescimento de algodoeiros submetidos à adubação nitrogenada. 
O porte do algodoeiro desejável é de 100 a 120 $\mathrm{cm}$ de altura e, portanto, a altura média obtida na avaliação aos 90 DAE é considerada adequada. São concordantes com estes resultados também os dos trabalhos de Lamas e Staut (2005), que obtiveram resultados semelhantes quando avaliaram altura de plantas de algodão em resposta à adubação nitrogenada associada à aplicação do cloreto de mepiquat. Em adição, pode-se afirmar que a redução de crescimento do algodoeiro é desejável, pois as plantas se tornam mais compactas, sendo facilitada a colheita mecânica (Athayde e Lamas, 1999; Lamas et al., 2000).
A massa média em capulhos, a massa média de 100 sementes e a produtividade do algodão com caroço foram significativamente influenciadas pela aplicação de cloreto de mepiquat, mas o estande final e o índice de produtividade e precocidade não (Tabela 2). Não foi observado qualquer efeito de interação entre regulador de crescimento $\mathrm{x}$ doses de $\mathrm{N}$ (Tabela 2).

O estande final médio foi de 6,5 plantas $\mathrm{m}^{-1}$, considerado adequado por estar bem próximo ao recomendado, que é de aproximadamente 7 plantas $\mathrm{m}^{-1}$ (Tabela 2).

Tabela 2. Valores médios das características do algodoeiro cv. FMX 986 em função de doses de N, na presença e ausência do cloreto de mepiquat. Ipameri (GO), 2005/2006

\begin{tabular}{|c|c|c|c|c|c|}
\hline Fatores & $\begin{array}{l}\text { Estande } \\
\text { Final }\end{array}$ & $\begin{array}{c}\text { Massa } \\
\text { Capulho }\end{array}$ & $\begin{array}{c}\text { Massa de Cem } \\
\text { Sementes }\end{array}$ & $\begin{array}{l}\text { Produtividade } \\
\text { caroço }\left({ }^{1}\right)\end{array}$ & $\begin{array}{c}\text { Índice de produtividade } \\
\text { e precocidade }\end{array}$ \\
\hline & $5 \mathrm{~m}^{2}$ & +2 & 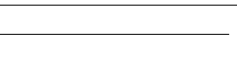 & $\mathrm{kg} \mathrm{ha}^{-1}$ & \\
\hline Ausência & 65 & $6,2 \mathrm{~b}$ & $8,9 \mathrm{~b}$ & $3360,2 \mathrm{~b}$ & 1,4 \\
\hline Presença & 65 & $6,7 \mathrm{a}$ & $9,4 \mathrm{a}$ & $3761,8 \mathrm{a}$ & 1,4 \\
\hline Média & 65 & 6,5 & 9,2 & 3561,0 & 1,4 \\
\hline CV (\%) & 14,3 & 5,3 & 3,5 & 19,1 & 9,6 \\
\hline
\end{tabular}

Médias seguidas por letras diferentes, na coluna, diferem entre si pelo teste $\mathrm{F}$ a $5 \%$ de probabilidade.

$\left({ }^{1}\right)$ Produtividade de algodão com caroço; pluma + caroço.

Apesar das massas médias de capulhos e de sementes serem características genéticas, ou seja, com pouca influência do ambiente, houve efeito dos tratamentos nelas. Este comportamento é confirmado pelos resultados promovidos pela aplicação de cloreto de mepiquat desde os estádios iniciais de desenvolvimento das plantas, por ter propiciado mais desenvolvimento dos órgãos reprodutivos nos ramos laterais, em detrimento do desenvolvimento em altura, tornando melhor o aproveitamento dos assimilados pelos frutos. Tais resultados são concordantes aos obtidos por Athayde e Lamas (1999) e Lamas et al. (2000), que obtiveram mais massa média de capulhos e de sementes em resposta à adição do cloreto de mepiquat.

Com relação às doses de $\mathrm{N}$, os maiores valores de massas médias de capulhos $(6,7 \mathrm{~g})$ e de sementes $(9,5 \mathrm{~g})$, foram obtidos com a utilização de $120 \mathrm{~kg}$ de $\mathrm{N} \mathrm{ha}^{-1}$ (Figura 4). Ressalta-se que estes valores são condizentes com os obtidos por VIEIRA et al. (2003), nos quais se detectou efeito da adubação nitrogenada nas massas médias de capulhos e de cem sementes.

Com a utilização do regulador proporcionouse acréscimo na produtividade de algodão com caroço da ordem de $12 \%$, em relação à testemunha (Tabela 2), o que pode ser atribuído ao aumento dos números de ramos reprodutivos, em detrimento dos vegetativos, conforme relato anterior. Já a maior produtividade do algodoeiro $\left(3.633 \mathrm{~kg} \mathrm{ha}^{-1}\right)$, em resposta à adubação nitrogenada, foi com o uso de $131 \mathrm{~kg} \mathrm{ha}^{-1}$ de $\mathrm{N}$ (Figura 5). A menor produtividade sem a utilização de $\mathrm{N}$ $\left(3.362 \mathrm{~kg} \mathrm{ha}^{-1}\right)$ é característica de um ambiente menos favorável à cultura e que pode explicar, pelo menos parcialmente, a maior magnitude de resposta.

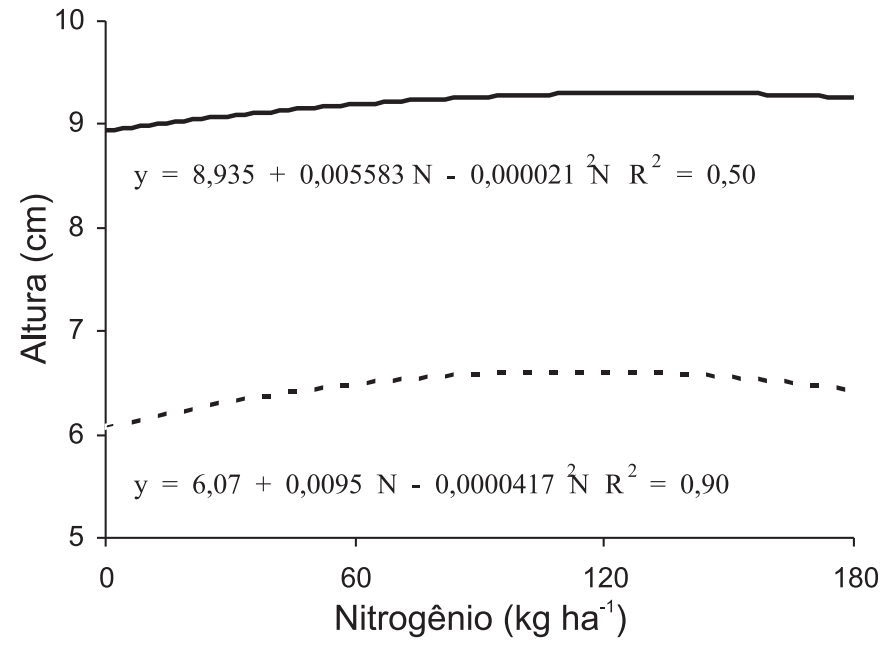

Figura 4. Massa de capulhos (__ $)$ e massa de cem sementes (_-_-_) de algodão cv. FMX - 986, em função de doses de $\mathrm{N}$, na presença de cloreto de mepiquat. Ipameri (GO), 2005/2006. 


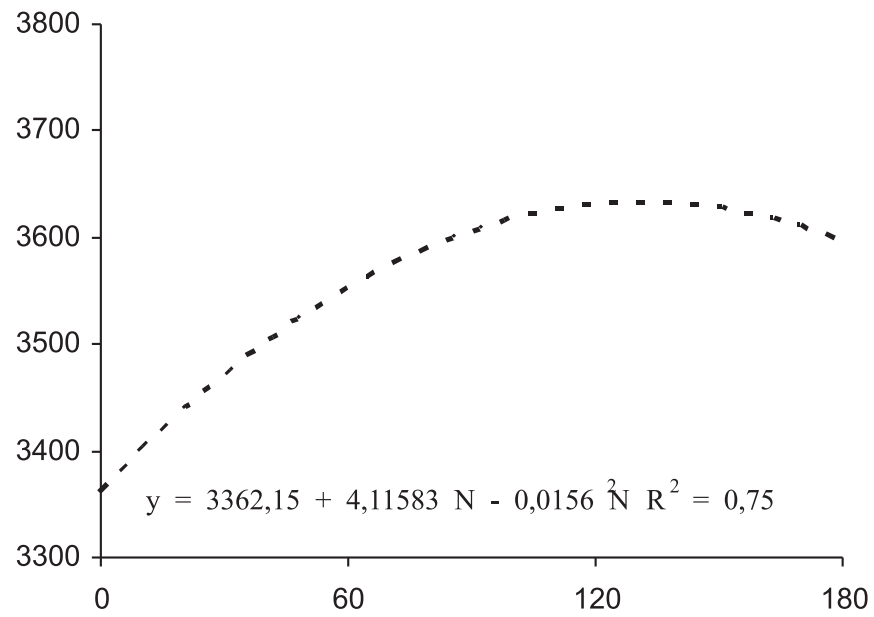

Figura 5. Produtividade de algodão em caroço (pluma + semente) do cv. FMX - 986, em função de doses de N, na presença de cloreto de mepiquat. Ipameri (GO), $2005 / 2006$.

Esses resultados são indicativos da necessidade de reavaliação das atuais recomendações oficiais de adubação nitrogenada para o algodoeiro. Corroboram para esta afirmação os resultados constatados por Silva et al. (2001a) e LAMAS e STAUT (2005), que obtiveram efeito no algodoeiro à adição de até $150 \mathrm{~kg} \mathrm{ha}^{-1}$ de $\mathrm{N}$.

A produtividade média obtida do algodão com caroço $\left(3.544 \mathrm{~kg} \mathrm{ha}^{-1}\right)$ foi superior à produtividade média do algodão no Brasil, em torno de $3.100 \mathrm{~kg} \mathrm{ha}^{-1}$, porém, próxima das médias de produtividade obtidas no cerrado, $3.540 \mathrm{~kg} \mathrm{ha}^{-1}$ (CONAB, 2008). Deste modo, a satisfatória produtividade obtida no cerrado pode ser resultado das condições climáticas e do adequado nível tecnológico adotado pelos produtores.

A não-detecção do efeito significativo da interação regulador $\mathrm{x}$ doses de $\mathrm{N}$ no rendimento do algodoeiro, certamente se deve à influência de outros fatores do meio, como variação genotípica, condições edafoclimáticas e tratos culturais aplicados à lavoura.

O índice de produtividade e precocidade não foi influenciado pelos tratamentos, sendo discordante dos resultados observados por LAMAS e STAUT (2005), pois, com a utilização do cloreto de mepiquat, associado à adubação nitrogenada, não foram promovidos acréscimos no índice de produtividade nem a antecipação do período de colheita do algodoeiro. Esse fato mostra que o efeito de $\mathrm{N}$ no crescimento e na produtividade do algodoeiro é dependente de outros fatores como temperatura, umidade e luminosidade.

\section{CONCLUSÕES}

1. A massa média de capulhos, a massa média de cem sementes e a produtividade do algodoeiro são incrementadas por doses crescentes de $\mathrm{N}$.

2. Com a aplicação do regulador de crescimento, diminui a altura da planta e promovemse acréscimos de rendimento no algodoeiro da ordem de $12 \%$. Os maiores valores de rendimento são obtidos com a dose de $131 \mathrm{~kg} \mathrm{ha}^{-1}$ de N;

3. Não há influência do regulador de crescimento e da adubação nitrogenada no índice de produtividade e precocidade do algodoeiro.

\section{REFERÊNCIAS}

ATHAYDE, M.L.F.; LAMAS, F.M. Aplicação seqüencial de cloreto de mepiquat no algodoeiro. Pesquisa Agropecuária Brasileira, Brasília, v.34, n.3, p.369-375, 1999.

BELTRÃO, N.E.M. Análise de crescimento não destrutiva. Campina Grande: EMBRAPA/CNPA, 1998. 20p. (Boletim Técnico, 52)

BONDADA, B.R.; OOSTERHUIS, D.M.; NORMAM, R.J.; BAKER, V.H. Canopy photossynthesis, growth, yield and bol ${ }^{15} \mathrm{~N}$ accumulation under nitrogen stress in cotton. Crop Science, Madison, v.36, n.1, p.127-133, 1996.

CONAB - COMPANHIA NACIONAL DE ABASTECIMENTO. Produto: algodão em pluma - informativo especial. Disponível em: <http:/ / www.conab.gov.br. > Acesso em: 15 mar. 2008.

EMBRAPA - EMPRESA BRASILEIRA DE PESQUISA AGROPECUÁRIA. Centro de Pesquisa Agropecuária do Oeste. Algodão: informações técnicas. Dourados-MS: EMBRAPACPAO; Campina Grande: EMBRAPA-CNPA, 1998. 217p. (Circular Técnica, 7)

EMBRAPA - EMPRESA BRASILEIRA DE PESQUISA AGROPECUÁRIA -. Centro Nacional de Pesquisa do Algodão. Cultivares de algodão para uso no cerrado safra 2003/2004. Disponível em: <http:/ / www.cnpa.embrapa.br.> Acesso em: 02 nov. 2004.

FURLANI JÚNIOR, E.; SILVA, N.M.; CARVALHO, L.H.; BORTOLETTO, N.; SABINO, J.C.; BOLONHEZI, D. Modos de aplicação do regulador vegetal no algodoeiro, cultivar IAC22, em diferentes densidades populacionais e níveis de nitrogênio em cobertura. Bragantia, Campinas, v.62, n.2, p.227233, 2003.

LAMAS, F.M. ; ATHAYDE, M.L.F. ; BANZATTO, D.A. Reações do algodoeiro CNPA - ITA 90 ao cloreto de mepiquat. Pesquisa Agropecuária Brasileira, Brasília, v.35, n.3, p.507-516, 2000.

LAMAS, F.M. Estudo comparativo entre cloreto de mepiquat e cloreto de chlormequat aplicados no algodoeiro. Pesquisa Agropecuária Brasileira, Brasília, v.36, n.2, p.265-272, 2001. 
LAMAS, F.M.; STAUT, L.A. Nitrogênio e cloreto de mepiquat na cultura do algodoeiro. Revista Ceres, Viçosa, v.51, n.298, p.755-764, 2005.

NÓBREGA, L.B.; VIEIRA, D.J.; BELTRÃO, N.E.M.; AZEVEDO, D.M.P.; OLIVEIRA, J.N. Efeito do regulador de crescimento cloreto de mepiquat na cultura do algodoeiro herbáceo no sertão paraibano. Revista Brasileira de Oleaginosas e Fibrosas, Campina Grande, v.3, n.2, p.89-92, 1999.

PEDROSO NETO, J.C.; FALLIERI, J.; LANZA, M.; SILVA, N.M.; LACA, J.B. Algodão. In: RIBEIRO, A.C.; GUIMARÃES, P.T.G.; ALVAREZ V., V.H. Recomendações para o uso de corretivos e fertilizantes em Minas Gerais - 5. ${ }^{\text {a }}$ Aproximação. Viçosa: CPSEMG, 1999, p.278-279.

PÍPOLO, A.E.; ATHAYDE, M.L.F.; PÍPOLO, V.C.; PARDUCCI, $\mathrm{S}$. Comparação entre diferentes doses de cloreto de clorocolina, aplicadas em algodoeiro herbáceo. Pesquisa Agropecuária Brasileira, Brasília, v.28, n.8, p.915-923, 1993.

REDDY, K.R.; BOONE, M.L.; REDDY, A.R. HODGES, H.F.; TURNER, S.B.; McKINION, J.D. Developing and validating a model for plant growth regulator. Agronomy Journal, Madison, v.87, n.6, p.1100-1105, 1995.

SILVA, M.N.B.; PITOMBEIRA, J.B.; BELTRÃO, E.M.; SILVA, F.P. População de plantas e adubação nitrogenada em algodoeiro herbáceo irrigado. I. Rendimento e característica da fibra. Revista Brasileira de Oleaginosas e Fibrosas, Campina Grande, v.5, n.2, p.355-361, 2001a.

SILVA, M.N.B.; BELTRÃO, E.M.; PITOMBEIRA, J.B. População de plantas e adubação nitrogenada em algodoeiro herbáceo irrigado. II. Característica do crescimento. Revista Brasileira de Oleaginosas e Fibrosas, Campina Grande, v.5, n.2, p.363$371,2001 b$.

VIEIRA, R.M.; MEDEIROS, A.A.; AMORIM, J.A.; FONSECA, F.C.E. Influencia do nitrogênio sobre as características da fibra, retenção frutífera e componentes da produção do algodoeiro. Revista Brasileira de Oleaginosas e Fibrosas, Campina Grande, v.7, n.1, p.641-646, 2003. 